\title{
INFANT HEALTH PRODUCTION FUNCTION: ROLE OF PRENATAL CARE
}

\author{
Heni Wahyuni \\ Faculty of Economics and Business, Universitas Gadjah Mada \\ (hwahyuni@ugm.ac.id)
}

\begin{abstract}
This article reviews the economic concept of the health production function regarding the determinants of infant health and the results of previous empirical studies on the role of prenatal care in infant health production. The review will include a brief explanation about the health production function, followed by how the concept applies to infant health, explaining the derivation of the infant health production function, and finally the previous empirical studies on the role of prenatal care in infant health production. Grossman's model on the demand for health and the framework of the infant health production function of Rosenzweig and Schultz explain that the following important factors will influence infant health and the demand for maternal medical care: age, wage/income, education, and knowledge. Furthermore, given that an infant inherits its health capital stock from its mother, there may be biological factors (e.g., a specific health endowment) that may be keys to determining infant health. In terms of the role of prenatal care, the review summaries that there is strong evidence that prenatal care does affect infant health. However, it is difficult to isolate the causal effect between the two without controlling for endogeneity, such as via a natural experiment. It is possible that there are unobserved heterogeneous factors of mothers that can affect prenatal care and infant health. Many studies have attempted to estimate the infant health production function, taking into account these selection biases. The merits and critiques of existing methods have also been discussed in the previously mentioned studies, which have mostly been conducted in relation to developed countries and have very rarely been conducted for the developing countries' context. The findings of this review state that studies into this topic should consider many important aspects, such as selectivity bias, the determinants of infant health as stated in theory and previous empirical studies, and the need to use an appropriate measurement of adequate prenatal care, especially for the case of developing countries.
\end{abstract}

Keywords: health production function, infant health production function, Grossman model, prenatal care

\section{INTRODUCTION}

This paper reviews the economic concept of the health production function regarding the determinants of infant health and the results of previous empirical studies on the role of prenatal care in infant health production. A brief review of the health production function will be included in the first section, followed by how the concept applies to infant health, explaining the derivation of the infant health production function, and finally the previous empirical studies on the role of prenatal care in infant health production.
There are a growing number of empirical studies that estimate the determinants of infant health (Conway \& Kennedy, 2004; Grossman \& Joyce, 1990; Joyce, 1994, 1999; Kaestner et.al, 1996; Lien \& Evans, 2005; Reichman et al., 2009; Rosenzweig \& Schultz, 1983; Steer, 2000; Warner, 2003). These studies are based on the framework of the infant health production function of Rosenzweig and Schultz (Rosenzweig \& Schultz, 1982; Rosenzweig \& Schultz, 1983), derived from the household or family production function. The prenatal care discussion explains the role of prenatal care that enters into the infant health production function from previous 
empirical studies. The relative merits and critiques of the factor will be considered and will be discussed as a base for further empirical studies.

\section{THE HEALTH PRODUCTION FUNCTION}

According to the classical demand theory of consumer behaviour, each consumer has a utility function that allows him/her to choose the combinations of consumption goods and services that can be purchased in the market. The consumer is assumed to be able to select the combinations that maximize his/her utility, subject to income and other resource constraints. This theory, therefore, explains the demand for goods and services, in general, by the consumer. When buying medical care, however, it is not the services, per se, that consumers demand; rather, they want better health (Grossman, 1972). Therefore, health is one of the choices in the utility function and medical care is an input to produce that choice. This distinction, between the demand for health and medical care, is the focus of Grossman's model for health.

Grossman used the human capital theory as an approach to explain the demand for health and medical care. The conceptual framework of human capital was introduced by Becker (Becker, 1965). Human capital includes qualities, such as knowledge and skills, that will influence productivity in the market and household sectors. Human capital can be increased by investing, for example, in education. Becker's model demonstrated that an increase in human capital will increase productivity in the market and household sectors and, thus, the knowledge that a person has will determine his/her market and household sector productivities. Following Becker's model, Grossman suggested health as one form of human capital (Grossman, 1972). Likewise, a person's stock of health capital will determine the total amount of time (healthy days) that can be spent in market and nonmarket activities. ${ }^{1}$

\footnotetext{
${ }^{1}$ Market activities are activities that produce earnings/ income and non-market activities include household sector and other activities; for example, recreation (an individual needs time and transportation services to create a recreational visit), additional knowledge (an
}

Health, however, differs from other forms of human capital, since an individual will demand it for two reasons: the first relates to a consumption commodity and, the second, to an investment commodity. As a consumption commodity, health enters the utility function directly as 'healthy days', which are a source of utility (and 'sick days' are a source of disutility). As an investment commodity, health will affect an individual's stock of health capital. The increase in the stock of health capital will increase the individual's healthy time that can be spent in market and non-market activities. In other words, the increase in the stock of health capital will increase the number of healthy days available each year if, for example, time were measured in years, and it will decrease the number of sick days each year (therefore, Grossman assumed that sick time, which is time lost from market and non-market activities due to illness or injury, is inversely related to the stock of health capital). The stock of health capital, ultimately, will determine the length of time that an individual remains healthy.

In the Grossman model of health capital, health is one choice in the utility function of an individual, a function of the total consumption of health "services" (Grossman conceptualized the flow from the health stock as a type of service) and the consumption of other commodities. In this model, it is assumed that a person has inherited an initial stock of health capital. This capital depreciates over time, and the rate of depreciation varies, depending on the age of the individual within his/her life cycle. The stock of health capital can be increased by an individual by investment. The inputs to produce this investment includes his/her own time and healthy behaviours (e.g., accessing medical care, maintaining a healthy diet, and exercise) and limiting unhealthy behaviour (e.g., smoking, illicit drug use and alcohol, and the quality of housing). Individuals also use market goods and their own time inputs to produce other commodities that may enter their utility function. Other factors, such as the level of education, can influence the

individual uses books and educational services to add to knowledge and/or skills). 
efficiency in the production of other commodities.

From the individual's point of view, the inputs to production are scarce resources subject to budget constraints (expenditure on these inputs must not exceed the budget/income constraint). The total amount of time available must be exhausted by all possible uses, which could be time spent working, time lost due to illness or injury, time as an input to the investment in health capital, and time as an input to produce other commodities, including household goods. Individuals try to maximize their utility, subject to their scarce resources and budget constraints. This produces the optimal quantity of investment in health capital and the optimal quantity of other commodities.

Grossman explained that the optimal stock of health capital, as an investment commodity, was determined by the equilibrium between the marginal monetary rate of return on investment in health (i.e., benefits of investment) and the user costs of health capital in terms of the price of investment. The marginal monetary rate of return on investment is defined as the value of the marginal product of health capital, divided by the marginal cost of the investment in health. The value of the marginal product of health capital is the wage rate, multiplied by the marginal product of health capital. The marginal product of health capital is the increase in the number of healthy days, caused by a one-unit increase in the stock of health capital. The net-user costs of health capital include the interest rate, the depreciation rate of health capital, and the capital gain. The user costs of health capital can be termed as the 'opportunity costs' of health capital. The interest rate measures the interest payment the individual foregoes, if he/she wants to increase his/her health capital stock by one unit rather than the stock of some other asset in a given period.

Some important factors, however, can alter the optimal stock of health. The first factor is age. It is assumed that the rate of depreciation increases with age - at least after some point in an individual's life cycle. As an individual becomes older, his/her physical strength and memory capacity will deteriorate. The increasing depreciation rate will reduce the individual's stock of health capital, which can then be offset by increasing his/her investment in health. Therefore, the demand for medical care - as one of the investment inputs into health - will increase with age, as long as the price elasticity of the demand for health capital is less than one. In other words, there is a negative relationship between health capital and medical care. The model predicts that unhealthy (old) people will make a larger investment and, therefore, will make use of more medical care than healthy (young) people.

The wage rate is another factor that can influence the optimal stock of health capital. As explained by Grossman, the stock of health capital will produce healthy days that the individual can use for working and earning an income. The amount of income the individual can earn is determined by his/her wage rate, multiplied by the number of healthy days he/she has available for working. The wage rate measures the value of healthy time, as it is the rate at which he/she can turn this healthy time into income. If there is an increase in the wage rate, the monetary value of the marginal product of health capital will increase, since the value of the marginal product of health capital is equal to the marginal product of health, multiplied by the wage rate. In other words, the higher the individual's wage, the higher the value to that individual, ceteris paribus, of an increase in healthy time. However, an investment in health capital requires time, and the cost of time has, also, to increase as the wage rate increases. Time is not the only input into an investment in health capital, there are other inputs required for an investment in health capital; for example, medical care fees. Thus, the cost of the investment will increase, but by a lower amount than the increase in the return on the investment. With no change in the user costs of health capital, the optimal health capital stock will rise, as the wage rate rises.

To examine the impact of education on the optimal stock of health capital, Grossman assumed that the investment in health required inputs: medical care, an individual's own time, 
and education. Grossman assumed that the investment in health was homogeneous to the degree of one of two inputs, i.e. medical care and the individual's own time. ${ }^{2}$ It follows that a change in an investment in health, caused by a change in education (the marginal product of education) is the sum of the changes in the marginal products of medical care and own time, with respect to the change in education. ${ }^{3}$ The marginal product of medical care is the increase in the number of healthy days, caused by a oneunit increase in medical care; and the marginal product of an individual's own time is the increase in the number of healthy days, caused by a one-unit increase in his/her own-time use. If education increases productivity (the marginal product of education is positive), an increase in education will increase the marginal products of both medical care and the individual's own time. As the marginal products of both inputs increase, the quantity of the inputs required to produce a given amount of investment is reduced. This means that the more educated people are, the more efficient they will be in using their own time and medical care as inputs to invest in their own health. If there is no price change in inputs into this investment, the reduction in their quantity will reduce the marginal cost of investment in health. This reduction in producing health capital will increase the marginal monetary rate of return on health investments. Given that the value of the marginal product of health capital is held constant (e.g., assuming that the wage rate is constant), the increase in the marginal monetary rate of return on the investment will increase the optimal stock of health capital. This increase, gained through more efficient production, will motivate better educated individuals and result in reducing medical care consumption.

\footnotetext{
${ }^{2} \mathrm{I}=\mathrm{f}(\mathrm{M}, \mathrm{TH}, \mathrm{E}) \ldots(1)$

where I is an investment in health; $\mathrm{M}$ is medical care; TH is the individual's own time; $\mathrm{E}$ is education.

$\mathrm{I}$ is homogeneous of degree one in M and TH. It means I

$=\mathrm{M}_{\mathrm{MP}} \mathrm{M}+\mathrm{TH} \cdot \mathrm{MP}_{\mathrm{TH}}$.....(2)

$\mathrm{MP}_{\mathrm{M}}$ is the marginal product of medical care and $\mathrm{MP}_{\mathrm{TH}}$ is the marginal product of own time.

${ }^{3}$ Differentiate equation (2) with respect to $\mathrm{E}$ (holding M and $\mathrm{TH}$ are constant) result in:$$
\frac{\partial I}{\partial E}=\frac{\partial\left(M P_{M}\right)}{\partial E} M+\frac{\partial\left(M P_{T H}\right)}{\partial E} T H
$$

Education, of course, is a determinant of other socioeconomic factors, such as wage/income or occupation, where wage/income grows as education increases. Therefore, the impact of education on health could reflect, in part, an impact on various socioeconomic characteristics (Grossman, 1999).

The Grossman model is an important approach to understanding how individuals make decisions about their health. It defines the concept of the health production function and explains why individuals invest in health-promoting activities. It concludes that the individual is able to use, and invest in, his/her health capital, as well as earn a return from it. What Grossman does not explain, however, is from where the initial stock of capital originates; rather, it is only assumed; nor does the model address the determinants of an infant's inherited health stock.

\section{INFANT HEALTH PRODUCTION FUNC- TION}

Individuals will inherit different levels of a starting (or initial) stock of health capital. The initial stock in an infant, in turn, will influence the length and health of its life. A new infant, however, cannot make its own health-investment decisions with the initial stock it inherits. This section will apply the concept of consumer behaviour and the health production function to explain the relationship between a mother's investment in her own health and that of her infant.

As per the Grossman approach, a woman will value her health capital for its investment aspect and for the 'consumption' of good health. When a woman is pregnant, her own state of health undergoes changes; therefore, she may need to increase the investment in her own health capital. It can be expected that she will have an increased demand for medical care (and, possibly, for other inputs into her health production), thus benefiting from this consumption and the value from the investment. Furthermore, during pregnancy, any investment in a woman's own health is, in parallel, an investment in her infant's health - infant health is a joint product. 
The consumption value from the health of her baby enters her utility function, since she will be happier if her baby is in good health. Therefore, we can expect a higher investment in her health production than would be explained by her health capital, alone.

As per the Grossman model, a woman will invest in her health capital to the extent where the marginal monetary rate of return on investment (i.e., benefits of investment) equals the user-costs of health capital. The investment in the infant's health will require inputs, such as medical care and the mother's own time and healthy behaviour. ${ }^{4}$ From a mother's point of view, those inputs are scarce, and she also has a limited budget. Therefore, to maximize her utility, she will have to determine the optimum investment in her infant's health within those constraints.

The return on investment in health capital is higher for women who have children than for those who do not because, for a woman with a baby, there is a return with regard to her own number of healthy days and in the healthy days for her infant (since the infant inherits its health capital from its mother), compared to a woman with no baby. The higher the return due to the additional number of a baby's healthy days, the fewer the days a mother will need to care for a sick infant. She can then benefit from this additional time for her market and non-market activities (she does however, faces budget constraints). This investment can provide the necessary initial health capital stock for the infant as a return, which will ultimately contribute to its own life, but the mother will not be able to benefit from it. The inability to benefit from the investment may be a deterrent for mothers to invest in infant health. Government policymaking should be able to correct this, if it is particularly concerned about maternal and infant health in Indonesia.

Grossman's concept of the health production function (1972) has been applied to the devel-

\footnotetext{
${ }^{4}$ Grossman focused on medical care and time as direct inputs and education as an indirect input. The change in indirect input changes the efficiency of the production process.
}

opment of a framework for the production of infant health (Corman \& Grossman, 1985; Corman et al., 1987; Grossman \& Joyce, 1990; Joyce, 1994; Reichman et al., 2009; Rosenzweig \& Schultz, 1982; Rosenzweig \& Schultz, 1983). The framework, based on the Rosenzweig and Schultz studies (1982; 1983), specified a model of infant health production function in the context of the family or household production. It was assumed that the health of the infant, $\mathrm{H}$, is one of the 'goods' in the family utility function. Other goods included consumer goods which affect infant health, Y (e.g., parental smoking, the number of children in the family), and health-neutral consumer goods, $\mathrm{X}$, which had no effect on infant health. The health of the infant depended on the level of consumer goods $(Y)$ and other family inputs $(Z)$ that were purchased as inputs of infant health, such as medical care. Thus, the family utility function is

$$
\mathrm{U}=\mathrm{U}(\mathrm{X}, \mathrm{Y}, \mathrm{H})
$$

The relationship between infant health and the inputs that influence it is explained by an infant health production function,

$$
\mathrm{H}=\mathrm{F}(\mathrm{Y}, \mathrm{Z}, \mu), \mathrm{F}_{\mathrm{Y}}, \mathrm{F}_{\mathrm{Z}}, \mathrm{F}_{\mu} \neq 0
$$

where $\mu$ relates to unobserved biological or endowment factors, such as genetic or environmental conditions, unaffected by parental behaviour, but known to the parents.

The family has budget constraints,

$$
\mathrm{I}=\mathrm{XP} \mathrm{P}_{\mathrm{X}}+\mathrm{YP}_{\mathrm{Y}}+\mathrm{ZP} \mathrm{P}_{\mathrm{Y}}
$$

where $\mathrm{P}_{\mathrm{X}}, \mathrm{P}_{\mathrm{Y}}$, and $\mathrm{P}_{\mathrm{Z}}$ are the prices of goods $\mathrm{X}$, $\mathrm{Y}$, and $\mathrm{Z}$.

The family attempts to maximize utility function (1), subject to (2) and (3). This maximization yields three demand equations of three types of goods $(\mathrm{X}, \mathrm{Y}$, and $\mathrm{Z})$ and the optimal infant health outcome $(\mathrm{H})$. Each demand equation is a function of prices, income, and unobserved endowment factors.

Following the Grossman model, the optimal stock of infant's health capital can be changed by certain factors. The first relates to the age of the mother, a choice variable that refers to the 
time in her life cycle, when she chooses to have a child (Rosenzweig \& Schultz, 1983). In terms of an infant's health production, the time when a mother decides to have a child can be treated as a behavioural factor. Biologically, the risks involved in pregnancy and birth are higher for very young, as well as for older women. The teenage years or very mature ages can be representative of unhealthy points in a mother's life cycle. At an older age, the Grossman model indicated that the rate of depreciation in a woman's health capital was higher (compared to an optimal reproductive age) and, therefore, the optimal stock of her health capital was lower than at the optimal reproductive age. By being pregnant at a younger age (than during the optimal reproductive age), a woman did not have a sufficient stock of health capital. Therefore, bearing children at a very old age or too young an age would contribute to women being less efficient investors in infant health. Since the baby would have inherited its stock of health capital from its mother, a change in the optimal health capital of the mother would, ultimately, influence that of the infant. The reduction in health capital can be offset by the mother, by making larger investments in infant health, driving her to consume more medical care than mothers who have babies at the optimal reproductive age.

Another factor that may change the optimal stock of an infant's health capital is the mother's wage rate: the higher the wage, the higher the increase in the value of her healthy time. This follows the Grossman model's prediction that was explained in the previous section, whereby an increase in wage leads to an increase in health capital investment, contributing to an increase in infant health. While the consumption value of infant health will not change, the higher the income a mother earns, the more she will invest in consumption, including infant health. An increase in income will also enable her to afford a better quality and quantity of health production inputs, such as medical care.

A mother's education is yet another factor which could change the optimal stock of an infant's health capital. Therefore, equation (2) can be rewritten to include education (Grossman \& Joyce, 1990; Joyce, 1994; Rosenzweig \& Schultz, 1982),

$$
\mathrm{H}=\mathrm{F}^{\prime}(\mathrm{Y}, \mathrm{Z}, \mu ; \mathrm{e}),
$$

where $\mathrm{e}$ is education and $\mathrm{F}_{\text {ye }}, \mathrm{F}_{\mathrm{ze}}>0$.

Then the optimization process of (1), subject to (3) and (4), yields the demand equations of three types of inputs goods (X, Y, and Z) that are functions of educational attainment, in addition to prices and income.

Conceptually, there are three potential mechanisms by which education can influence infant health. The first improves the efficiency in producing infant health (Grossman, 1972, 1999). Productive efficiency exists where the more educated mothers will either produce a larger amount of output (in this case, health), for given amounts of inputs, or will use inputs more efficiently (i.e., use less inputs) to produce a given quantity of investment in infant health. This will decrease the cost of the investment and increase infant health. It reflects the effect that schooling can have on infant health production, through the alteration of an input of the infant health production function (Rosenzweig \& Schultz, 1982; Rosenzweig \& Schultz, 1983). The second mechanism relates to the return to education, which can be quantified by an increase in wage or income. Educated women earn more, and they are able to afford more for medical care services (Currie \& Moretti, 2003). If the cost of medical care remains unchanged, the investment in infant health will increase and, thus, result in an increase in infant health capital. The third process relates to education and health information. Education can improve knowledge and the ability to acquire and process information, especially with regard to healthy behaviour during pregnancy. For example, highly educated people understand the importance of medical care and what constitutes a healthy lifestyle (e.g., appropriate diet, exercise, the harmful effects of tobacco and drugs, etc.). Education, therefore, may increase healthy behaviour in women ${ }^{5}$ and,

\footnotetext{
${ }^{5}$ Grossman focused on medical care as the market 'good' in the investment function. He also acknowledged, however, that there were generally other inputs, such as
} 
increase their use of medical care services (Currie \& Moretti, 2003). By understanding the importance of medical care and a healthy lifestyle, women may well be motivated to change their behaviour toward infant health.

\section{PRENATAL CARE UTILIZATION}

Prenatal care utilization is believed to be an important factor in ensuring that women have healthy pregnancies and babies. Through prenatal care, mothers can receive (i) early detection of an at-risk pregnancy or any potential complications and diseases; (ii) diagnosis and treatment for medical conditions that occur before and during pregnancy; (iii) vitamin, minerals, and other supplements for pregnancy; and (iv) advice and information related to improving nutrition during pregnancy, healthy behaviour, preventing potential difficulties, and advice regarding delivery (Berg, 1995). Care in early pregnancy and intense prenatal care may protect mothers from adverse birth outcomes. Adequate prenatal care visits can encourage healthy behaviour, prevent deterioration in the health of the mother and the foetus, and monitor for possible risks. During prenatal visits, mothers may be diagnosed with diseases and abnormalities that may be detrimental to the pregnancies and the pregnancy outcomes. Providing effective services and proper treatment will, therefore, contribute to preventing ill health, reduce risks, and increase the likelihood of a healthy baby.

Economists and health researchers, alike, have long been interested in the analysis of the effects of prenatal care on infant health. Most studies have been conducted in industrialized countries, where prenatal care has been shown to positively have an impact on birth outcomes (Grossman \& Joyce, 1990; Guilkey et al., 1989; Habibov \& Fan, 2011; Jewell \& Triunfo, 2006; Liu, 1998; Reichman et al., 2009; Reichman \& Florio, 1996; Rosenzweig \& Schultz, 1983; Rous et al.,, 2004). There are three important issues that will be reviewed in this section regarding this evidence. The first is the associa-

housing, diet, exercise, recreation, cigarette smoking, and alcohol consumption that influenced an individual's level of health. tion of adequate prenatal care on infant health, which is important to ensure that mothers have a healthy pregnancy and a healthy baby; however, there is still no generally agreed measure for the adequacy. The second issue will be a review of the determinants of prenatal care utilization, particularly on the barriers (commonly relating to policy decision-making in developing economies) that affect access to these services. The third and last issue is the fact that it is extremely difficult to observe the causal effects of prenatal care and infant health, despite the various measurements of prenatal care that have been used. This is because there may be unobserved exogenous factors that correlate with both prenatal care and outcomes, which may be known to individual mothers but are unknown to researchers. This problem is often referred to as 'selectivity' problems, which can impact the effectiveness of prenatal care on infant health.

\section{The Impact of Adequate Prenatal Care Visits on Infant Health}

Adequate care depends on both the timing and the number of visits. With regard to the effectiveness of such services, it is difficult to have a single measurement of a prenatal visit that will capture the effectiveness of the visit on birth outcomes. To estimate the adequacy of care, many studies use prenatal care delay (in months or weeks) or whether the mother has had prenatal care during the first trimester of pregnancy (Li \& Poirier, 2003b; Liu, 1998; Reichman et al., 2009). Others use the number of visits (sometimes with the squared root of the number of visits included in the model) (Joyce, 1994; Rous et al., 2004) as the measurement of prenatal care. Regardless of which indicator is applied, the findings have generally indicated that the earlier the visits start or the higher the number of visits there are, the better the birth outcome. In other words, the longer the delay in the utilization of prenatal care, the more possibility of an adverse birth outcome. Rosenzweig and Schultz (1983) considered the number of months of elapsed pregnancy before the mother visited a medical professional. They found that a 5 -month increase in the sample mean delay in 
seeking prenatal care services reduced the birthweight by 260 grams. Liu (1998) showed that for every month a mother delayed initiating care the birthweight reduced, on average, by 160 grams.

Current studies for developed countries reflect the following. Rous et al., 2004) found that one additional visit will increase birthweight by 14.44 grams, and Reichman et al. (2009), who used first-trimester prenatal care as another measurement, discovered that the baby's birthweight increased by about 50 grams in selfreported input (the authors also used actual input, which is the combination between selfreporting and information from medical records, and found an insignificant result). Those studies controlled the estimation for common demographic and socioeconomic factors, as well as the behaviour of the mothers during pregnancy. However, there have been only a few studies that have been conducted in developing countries. Generally, the results were similar, as were the measurements used, for developed countries. For example, Guilkey et al. (1989) used the number of visits and data from Metropolitan Cebu, the Philippines, and found that this factor had a significant influence on birthweight in relation to private health providers in urban areas. Jewell and Triunfo (2006), for the case of Uruguay, used the month of initiation of prenatal care and found consistency in the result with other studies.

Some studies used the Kessner index, which combines the timing of the visit, the number of visits, and the length of pregnancy in order to provide a measure of prenatal care visits as adequate, intermediate, or inadequate. For the Kessner index, adequacy is defined as prenatal care beginning in the first trimester, with nine visits for a normal length pregnancy; intermediacy is defined as prenatal care beginning in the second trimester; and inadequacy is defined as prenatal care starting in the third trimester or not at all (Kotelchuck, 1994). An example of a study, which used this index, is Joyce (1994). He divided the prenatal care that women received into three categories: inadequate, intermediate, and adequate. He found that the impact of prenatal care on birthweight was higher for mothers who moved from inadequate to intermediate than from intermediate to adequate care.

Another widely used measurement of the adequacy of care in developed countries is the two-factor Adequacy of Prenatal Care Utilization (APNCU) index. This index includes information about the timing for the initiation of prenatal care and the number of visits after initiation (Kotelchuck, 1994). Adequate care, based on this index, is defined as care having begun by the fourth month and 80-109 percent of recommended visits received. The recommended number of visits is based on the American College of Obstetricians and Gynecologists' (ACOG) recommendation, which is 14 visits during a normal-length pregnancy (40 weeks).

There are a number of critiques regarding the various measures for the adequacy of prenatal care. The first relates to the initiation of the first trimester visit or the month of initiation of the visit, which provide no data on the visits after the first trimester one. The second relates to the fact that in countries where prenatal care coverage is low, measures such as the Kessner and the two-factor APNCU index could be too high a standard, proving unrealistic and, therefore, irrelevant when they are unable to be met. For instance, using data from the 2007 IDHS, approximately 95 percent of women visited a prenatal care service at least once; however, only 66 percent went four times during pregnancy (Badan Pusat Statistik Republik Indonesia (Statistics Indonesia) \& Macro International, 2008). Therefore, both indices may be inappropriate in this case. The impact of any public health programme relating to prenatal care services - and, ultimately, birth outcome improvement - requires an appropriate measurement. Inappropriate standards may potentially underestimate the impact of care on the infant health production function.

When considering the appropriate measurement for countries with low prenatal care coverage and low prenatal care utilization, a minimum frequency of visits can be taken into account to ensure a healthy pregnancy and to detect any complications. The WHO recommends a minimum of four visits during pregnancy (World 
Health Organization, 2005, p. 43). Specifically, these should represent one in the first trimester (by 16 weeks), one in the second trimester (at 24-28 weeks), and two in the third trimester (at 32 weeks and at 36-38 weeks) of pregnancy (Berg, 1995). In the context of developing countries, this standard may be more appropriate than the other standards mentioned, whose frequency make them impracticable.

Despite the positive results of prenatal care in terms of infant health, as well as the benefits that have been identified for mothers, utilization of this care remains low in developing countries, including Indonesia. The following section will discuss the possible barriers and an analysis in search of an answer.

\section{Barriers to Prenatal Care Utilization}

In general, prenatal care use can be explained within two key frameworks: demand-side and supply-side factors (McNamee et al., 2009). Demand-side factors include cost (socioeconomic, such as income and education), women's autonomy in decision-making in the household, geography (distance between health providers and residence), demographics (age, marital status, and parity), and quality of care (anticipated and experienced satisfaction with the process of care and the final health outcomes). Supply-side factors include the level of accessibility of the services and the availability of qualified health providers. The following sub-section will explain some of the key elements for prenatal care utilization. Some factors already have been discussed, to some extent, in the section relating to determinants as indirect factors that influence infant health through the alteration of prenatal care utilization. I will discuss the determinants that focus on the barriers of utilization, caused by these factors. The discussion will attempt to identify how they constrain access to prenatal services, and it will include socioeconomic, geographic, and supply-side components.

\section{Socioeconomic Factors and the Decision- Making Power of Women in the Household}

Inequality in the use of maternal health care and delivery services, associated with socioeco- nomic inequality, exists across countries (Celik \& Hotchkiss, 2000; Gwatkin et al., 2007; Sepehri et al., 2008). Gwatkin et al. (2007) noted that prenatal care use increased steadily with rising economic power. The wealthiest 20 percent of the population used prenatal care at one and a half to two times the rate of the poorest 20 percent. The difference was even larger for visits to professional providers, with the wealthiest double to those of the needy. In Indonesia, visits by a higher-income person to a medically trained person in 2002/03 were 1.3 times higher than for a low-income person, and for iron supplementation during pregnancy, the ratio between the richest and the poorest was 1.4 (Gwatkin et al., 2007). The gaps were worse for deliveries attended by a medically trained person, with an almost three times difference between the two.

Many of the studies suggested that the socioeconomic status of women was one of the most important factors contributing to the use of prenatal care services (Celik \& Hotchkiss, 2000; McNamee et al., 2009; Nguyen et al., 2012; Sepehri et al., 2008). The indicators used vary from study to study, with a large number of them including the relationship between income or wealth of mothers and the use of prenatal care in terms of developing countries, providing conflicting results. An analysis (using the National Family Health Survey carried out in Southern India during 1992-93 and a standard-of-living index as a measurement of household wealth) found that the impact of the standard of living was significant in only one state (Navaneetham \& Dharmalingam, 2002). Celik and Hotchkiss (2000) used the 1993 Turkish Demographic and Health Survey and established that household wealth would affect prenatal care use from a trained provider, depending on the measure of household wealth. They found that only two indicators (owning a car and having a flush toilet) were significant. On the other hand, there have been studies undertaken that have found significant results for a broader range of measures. For instance, Gage (2007) examined the factors in rural Mali, using data from the 2001 Demographic and Health Survey, where 9,340 of 
12,849 women aged 15-49 years resided in rural areas. She also employed a household infrastructure index as an indicator of wealth. The index was derived from the infrastructure that belonged to a household, such as the source of drinking water and type of toilet. She found that household wealth did have a strong relationship with prenatal care use in the first trimester visit, and with four or more visits. Habibov (2011) used the Azerbaijan Demographic and Health Survey and found that mothers from the richest and richer households (derived from the household wealth index) made more visits. Finally, Muchabaiwa et al. (2012) examined the case for Zimbabwe, using the 2005/06 Zimbabwe Demographic Health Survey and the household wealth index. He discovered that the middle, richer, and richest households were more likely to use these services than the poorest.

There is one possible rationale to explain why the studies in these particular developing countries were found to be inconsistent in terms of the relationship between wealth and prenatal care. Most applied a household wealth index (a husband's income or household assets) as an indicator of the wealth of the mother. This may not be a true representative indicator to establishing the wealth or socioeconomic status of a woman in a household, since access to household assets is often difficult for women who do not have the bargaining power to make decisions with regard to using the assets for health care, which could prove to be an important factor. This also applies to money-spending decisions, sex, freedom of mobility, family domination, and decisions related to children's health. For example, in Indonesia, a woman who has a share of the household assets or has control over economic resources, has more control over her own reproductive health decisions and the use of prenatal care and delivery services, compared to those who do not (Beegle et al., 2001). It does appear, therefore, that involving mothers in the household decision-making related to the access to internal and external resources is an important factor in the improvement of reproductive health and the utilization of maternal health care services.
In addition to the wealth indicators of women, empirical studies reported that education impacts on their use of prenatal and postnatal care services (Beegle et al., 2001; Celik \& Hotchkiss, 2000; Currie \& Moretti, 2003; Guilkey et al., 1989; Reichman \& Florio, 1996; Rosenzweig \& Schultz, 1983). Economic literature, in general, suggests that the more educated the mothers are, the more knowledge of health and healthy behaviour they have, including their ability to process information. This implies that there are barriers that prevent the use of prenatal care in developing countries due to the low educational levels of women.

Overall, the socioeconomic status of mothers is crucial to the utilization of prenatal care. It is associated with wealth and education, factors that will influence policy decision-making in many developing countries. Inconsistent results that relate to wealth, however, may relate to the measure of wealth that the studies used or to the fact that the impact of wealth or income relates to education.

\section{Geographical Constraint}

Extensive research has demonstrated that the area where the mother resides can essentially influence her utilization of prenatal care (Celik \& Hotchkiss, 2000; Gage, 2007; Gage \& Calixte, 2006; Habibov, 2011; Kyei et al., 2012; Navaneetham \& Dharmalingam, 2002; Sepehri et al., 2008). This reflects the differences between urban and rural areas in the availability and accessibility of health care facilities. Women living in urban areas usually have better access than those in rural or remote locations. For urban women, there is an increase in the awareness of, and exposure to, a wide variety of quality health providers (Celik \& Hotchkiss, 2000; Sepehri et al., 2008) while, for those in rural and remote areas, access to modern health care is usually limited and is affected by distance and the lack of transportation. For example, in rural Zambia, for each increase of 10 kilometres, the odds of receiving quality prenatal care (defined as having more than four visits, with more than eight specific interventions) decreased by 25 percent (Kyei et al., 2012). Gage and Calaxite (2006) 
noted that the lack of service availability and poor road conditions reduced the frequency and timeliness of receiving such care in Haiti. Gage (2007) also found that in rural Mali, not only did transportation barriers affect facility use per the recommended frequency, but the lack of facilities prevented the first trimester visit. A comparison study of mothers in rural and urban areas of southern India came to similar conclusions (Navaneetham \& Dharmalingam, 2002), as did research relating to Azerbaijan (Habibov, 2011).

\section{Financial Assistance}

Out-of-pocket expenses often lead to inadequate prenatal care visits for poor women. In response, many programmes provide financial assistance in the form of insurance, vouchers, or subsidies to improve the use of services and promote infant health. Targeted programmes, such as Medicaid in the United States, are very common in developed countries and provide free services for low-income families, with the goal of improving infant health by increasing the quantity and quality of services for women (Kaestner, 1999). Similar programmes are increasingly being implemented in developing countries, such as Bangladesh, Indonesia, Nepal, and Turkey (Bhatia \& Gorter, 2007; Celik \& Hotchkiss, 2000; Johar, 2009; Nguyen et al., 2012).

Despite the growing data relating to the impact of financial assistance and related programmes, the evidence shows mixed results. For example, the study by Kaestner (1999) on U.S. Medicaid found that there was no significant association between insurance status and birthweight; i.e., no significant difference in birthweight for the uninsured, for Medicaid recipients and for women with private insurance (after controlling for other factors, such as socioeconomic and demographic characteristics, maternal health conditions, the previous number of stillbirths or miscarriages, race, and ethnicity). Kaestner found that women under Medicaid made less prenatal care visits and were less likely to have adequate care (as defined by the Kotelchuck (Kotelchuck, 1994) index) than those with private insurance. He argued that this was mainly due to the uninsured and Medicaid recipients beginning care later than the privately insured, although the difference was very small. Furthermore, findings relating to Medicaid and the quality of prenatal care suggest that there is no evidence that Medicaid recipients received less quality care than the privately insured.

Conflicting results come from Joyce's examination (Joyce, 1999) of the impact of the Prenatal Care Assistance Programme (PCAP) in New York, which was a part of the Medicaid programme. They showed that PCAP was associated with a 20-percent increase in the likelihood of enrolment into the Women, Infants and Children programme, 35 grams increase in mean birthweight, and a 1.3 percentage point decrease in the rate of low birthweight. A New Jersey Health Start programme analysis showed that black women, covered by Medicaid, gave birth to infants with a higher weight and, therefore, lowered newborn hospitalization costs (Reichman \& Florio, 1996).

The experience in developing countries also shows mixed results. A voucher programme in Bangladesh significantly increased the use of maternal health care services (Nguyen et al., 2012) through incentives for poor mothers to use antenatal, delivery, and postnatal services. Eligible women were granted access to the services for free. Participating health care providers also benefited from the programme. Results from the evaluation of the programme found that, compared to women in a control group (no voucher programme), the treatment group had a 46.4 percentage point higher probability of using a qualified provider and a 13.6 percentage point higher probability of delivery in a health care institution. The effect of this demand-side financing through a health care card, however, has been more limited in Indonesia (Johar, 2009), for which the author provides some explanations. First, the demand for public health care services is inelastic; i.e., given a change in price, there is little shift in the quantity of demand. Second, the variation in the level and lack of actual information about the programme's scope and objectives may have contributed to the programme's negligible impact on health care service use. Last, 
where there is an inadequate health care system and public health facilities are limited, an increase in demand cannot be accommodated. This leads to the selection of self-medication by the target community, in lieu of seeking public health care, causing underutilization of any such support programme. It is important, therefore, to improve the health system in tandem with any demand-side programme.

Out-of-pocket expenditure is one of the major barriers to accessing adequate prenatal care by poor mothers. Many programmes have responded by providing financial assistance in the form of either insurance, vouchers, or subsidies, especially in relation to poor families, to improve the use of prenatal care services and infant health.

\section{Selectivity Problems of Prenatal Care: Unobserved Heterogeneity}

Although there is consistent evidence of the relationship between prenatal care and infant health, the interpretation of causality must be treated with caution. This is because there are a range of possible unobserved factors that may influence prenatal care, as well as infant health. The population may differ with respect to health endowments and some of the differences would be known to the individuals but not to the researchers. For instance, many pregnant women have information about their health endowment from prior pregnancies (e.g., pregnancy complications, adverse birth outcomes), which may influence their use of prenatal care and, likewise, their birth outcomes. Women with poor health endowments may utilize more prenatal care services, while those with a positive health endowment may seek less care. In this case, the effects of prenatal care may be underestimated. Alternatively, women in better health may invest in more prenatal care, which could result in an overestimation of the effect of prenatal care. For example, pregnant women with good health endowments may exhibit more beneficial health behaviour. These women may initiate prenatal care early or make more visits, may take sufficient nutritious food, vitamin supplements, engage in proper exercise, and avoid unhealthy behaviour, compared to other groups.
If indicators of health endowment are unobserved, it may bias the estimated impact of prenatal care on infant health. Depending on the direction of the relationship between health endowment and health-seeking behaviour, the effectiveness of prenatal care may be overestimated or underestimated when the relationship between prenatal care and infant health is estimated using a direct correlation method. This will make it extremely difficult to estimate the independent effect of prenatal care on birth outcomes and to isolate the causal relationship between the two in non-experimental data. This problem is referred to in economic literature as an endogeneity of prenatal care. Ignoring this endogeneity in the estimation of infant health production may lead to an incorrect inference about the value of prenatal care utilization, and could mislead policymakers into believing that adequate or even additional prenatal care will not improve birth outcomes. They will consider the other inputs in the infant health production function - more amenable to policymaking rather than encourage the use of prenatal care.

Previous economic studies have used various tests and econometric methods to address the bias due to endogeneity in prenatal care. The most common method is the Two-Stage Least Squares (2SLS) or instrumental variables that counteract the Ordinary Least Squares (OLS) method. Beginning with Rosenzweig and Schultz's (1983) research, they found that there was no appreciable effect on prenatal care, according to the OLS method, while the effect using 2SLS was significant and almost forty times the OLS point estimate, when using the price of milk, a husband's income, and parental education as instruments for identification. The authors also suggested that the OLS result underestimated the prenatal care impact on birthweight because mothers who knew that their pregnancies could be problematic may have addressed their anticipation of adverse birth outcomes by seeking prenatal care early. Current studies tend to follow this work, using the 2SLS method with different instruments, such as marital status (Jewell \& Triunfo, 2006). 
Table 1. Summary of Empirical Studies on Infant Health and Prenatal Care

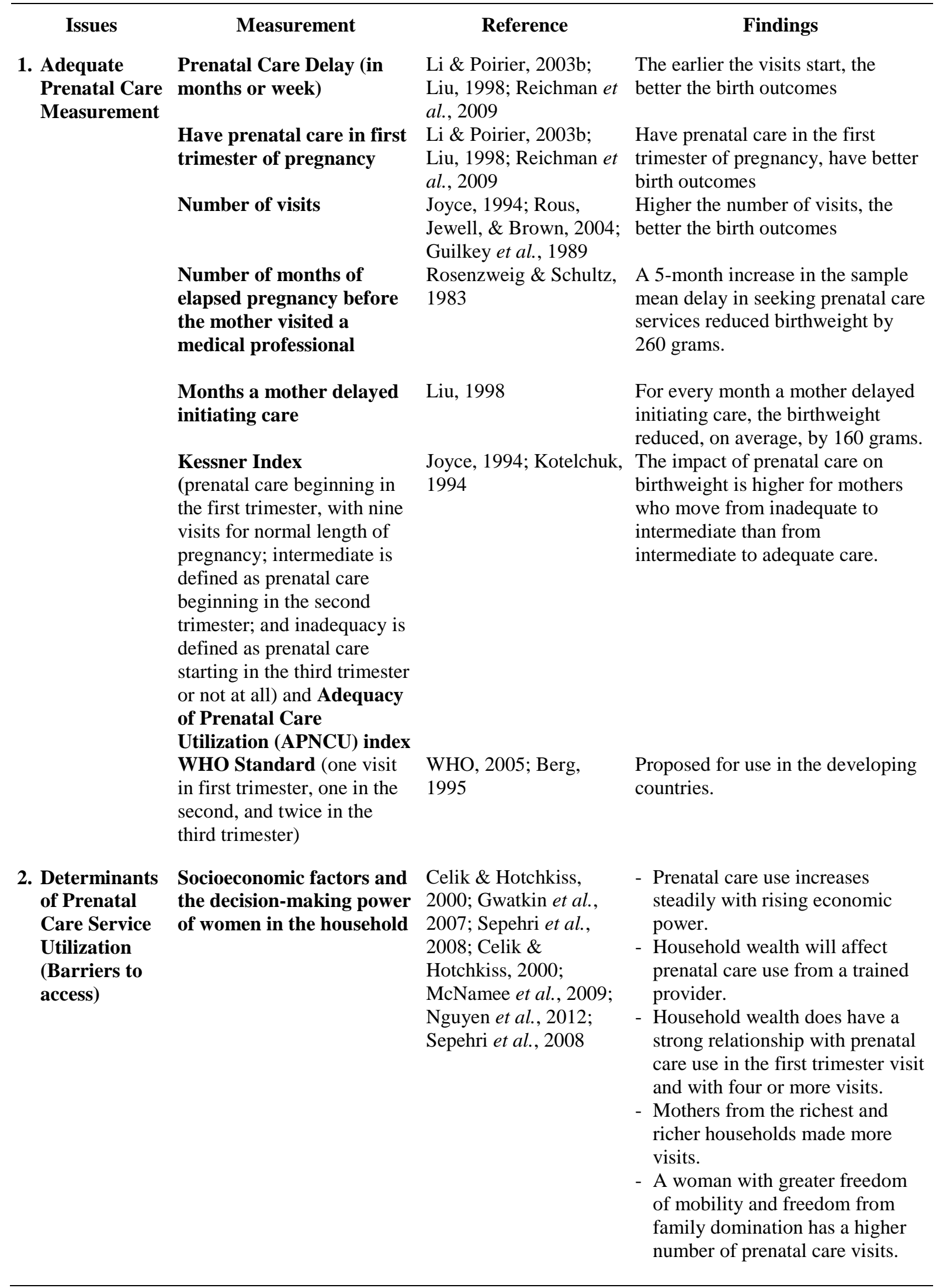




\begin{tabular}{|c|c|c|c|}
\hline & Geographical constraint & $\begin{array}{l}\text { Celik \& Hotchkiss, } \\
\text { 2000; Gage, 2007; } \\
\text { Gage \& Calixte, 2006; } \\
\text { Habibov, 2011; Kyei } \text { et } \\
\text { al., 2012; Navaneetham } \\
\text { \& Dharmalingam, } \\
\text { 2002; Sepehri et al., } \\
\text { 2008 }\end{array}$ & $\begin{array}{l}\text { - Women living in urban areas } \\
\text { usually have better access than } \\
\text { those in rural or remote } \\
\text { locations. } \\
\text { - The lack of service availability } \\
\text { and poor road conditions reduced } \\
\text { the frequency and timeliness of } \\
\text { receiving prenatal care. } \\
\text { - The lack of facilities prevented } \\
\text { the first trimester visit of prenatal } \\
\text { care. }\end{array}$ \\
\hline & Financial Assistance & $\begin{array}{l}\text { Kaestner, 1999; Bhatia } \\
\text { \& Gorter, 2007; Celik } \\
\text { \& Hotchkiss, 2000; } \\
\text { Johar, 2009; Nguyen et } \\
\text { al., 2012; Joyce, } 1999 .\end{array}$ & $\begin{array}{l}\text { - Mothers with financial } \\
\text { assistance use higher prenatal } \\
\text { care services. }\end{array}$ \\
\hline $\begin{array}{l}\text { 3. Causal effect } \\
\text { of prenatal } \\
\text { care and } \\
\text { infant health }\end{array}$ & $\begin{array}{l}\text { Endogeneity of prenatal } \\
\text { care }\end{array}$ & $\begin{array}{l}\text { Rosenweigz and } \\
\text { Schultz, 1983; Jewell \& } \\
\text { Triunfo, 2006; } \\
\text { Grossman \& Joyce, } \\
1990\end{array}$ & $\begin{array}{l}\text { - Rosenweigz and Schultz (1983) } \\
\text { suggested that OLS result } \\
\text { underestimates prenatal care } \\
\text { impact on birthweight. } \\
\text { - Jewell \& Triunfo (2006) found } \\
\text { that using 2SLS, prenatal care } \\
\text { was a statististically significant } \\
\text { influence in birth outcomes, but } \\
\text { they did not conduct endogeneity } \\
\text { test. } \\
\text { - Grossman \& Joyce (1990) found } \\
\text { that the endogeneity problem } \\
\text { only existed in relation to black } \\
\text { mothers. }\end{array}$ \\
\hline
\end{tabular}

Source: Primary Data, processed (2015)

There are some criticisms to be made about the 2SLS method. The first is the problem of identifying valid instruments for prenatal care. Two requirements are necessary for an instrument to be valid (Wooldridge, 2009): (i) it must be uncorrelated with unobserved factors in the infant health production function. In other words, it should not have a partial effect on infant health (referred to as instrument exogeneity); and (ii) it must be related to the endogeneous variable; i.e., prenatal care (referred to as instrument relevance, relevant in explaining variation). The usual variables used in the previous studies may not have fulfilled those requirements. For example, education, income, or marital status as instruments may be correlated with prenatal care. However, these variables may have only a partial effect on a baby's health. As discussed previously, education can affect infant health directly, explained as a prod- uctivity shifter in the production process. The same applies to income. Marital status is also a choice variable (as discussed previously). If these instruments partially correlate to infant health or weakly correlate to prenatal care, then the estimators that have appeared as a result of the 2SLS method could prove to be worse than those using the OLS method (Wooldridge, 2009).

The second critique is that the 2SLS estimator is less efficient than the OLS one, such that the standard errors of 2SLS estimators are usually larger than the OLS (Wooldridge, 2009). Therefore, it is important to have carried out an endogeneity test of prenatal care to show whether the 2SLS method is applicable. Some of the previous studies lacked this process (Jewell \& Triunfo, 2006).

Grossman and Joyce (1990) estimated the impact of prenatal care on birthweight, using a 
cohort of pregnant women in New York City in 1984 and taking into account the bias from endogeneity of prenatal care and pregnancy resolution. They found that there was a strong pregnancy-resolution bias for blacks, but not for whites. For blacks, the results suggested that the unobserved factors that caused birth probability were correlated with unobserved factors that decreased the delay in the initiation of prenatal care visits and increased birthweight, after controlling for education, the age of the mother, marital status, parity, availability of clinics, and abortion-related indicators. Their results also suggested that the endogenity problem of prenatal care was only evident for black mothers, after controlling for the same factors, plus unhealthy behaviour and the gender of the child. The authors argued that the mean shadow price of contraception and the variation of price were greater for blacks than for whites. Therefore, black women were more likely to abort than white women. For this reason, the selectivity bias was only found in relation to black mothers.

\section{CONCLUSION}

In conclusion, using Grossman's model on the demand for health (Grossman, 1972, 1999) and the framework of the infant health production function of Rosenzweig and Schultz (1982; Rosenzweig \& Schultz, 1983), the following important factors will influence infant health and the demand for maternal medical care, as described in the previous paragraphs: age, wage/income, education, and knowledge. Furthermore, given that an infant inherits its health capital stock from its mother, there may be biological factors (e.g., a specific health endowment) that may be key to determining infant health (Grossman \& Joyce, 1990; Joyce, 1994; Rosenzweig \& Schultz, 1982; Rosenzweig \& Schultz, 1983). In this research, the empirical analysis was based on the framework of the infant health production function. The equation below summarizes the production of infant health by the mother that is derived from the concept of the infant health production function framework,

$$
\mathrm{H}=\mathrm{h}\left(\mathrm{A}_{\mathrm{m}}, \mathrm{Y}_{\mathrm{m}}, \mathrm{I}_{\mathrm{m}}, \mathrm{E}_{\mathrm{m}}, \mathrm{B}_{\mathrm{m}}, \mu\right)
$$

where $A_{m}$ is the age of the mother, $Y_{m}$ relates to medical care, $I_{m}$ is income, wealth or wage, $E_{m}$ is the education of the mother, $B_{m}$ is maternal healthy/risky behaviour, and $\mu$ is the mother's specific health endowment. Age, income/wealth, and education are commonly known as socioeconomic and demographic factors.

In terms of the role of prenatal care, there is strong evidence that prenatal care does affect infant health. However, it is difficult to isolate the causal effect between the two without controlling for endogeneity, such as via a natural experiment. It is possible that there are unobserved heterogeneous factors of mothers that can affect prenatal care and infant health. Many studies have attempted to estimate the infant health production function, taking into account these selection biases. The merits and critiques of existing methods have also been discussed in the previously mentioned studies, which have mostly been conducted in relation to developed countries and have very rarely been conducted for the developing countries' context. Therefore, there is a need to observe the role of prenatal care on infant health production using a comprehensive approach for the case of developing countries.

It implies that studies on this topic should consider many important aspects, such as selectivity bias, the determinants of infant health that were stated in theory and in previous empirical studies and the need to use an appropriate measurement of adequate prenatal care, especially for the case of developing countries.

\section{REFERENCE}

Badan Pusat Statistik Republik Indonesia (Statistics Indonesia), \& Macro International, 2008. Indonesia Demographic and Health Survey 2007. Calverton, Maryland, USA: Statistics Indonesia and Macro International.

Becker, G. S., 1965. "A theory of the allocation of time". The Economic Journal, LXXV (299), 493-517. 
Beegle, K., E. Frankenberg, and D. Thomas, 2001. "Bargaining power within couples and use of prenatal and delivery care in Indonesia". Studies in Family Planning, 32(2), 130-146.

Berg, C. J., 1995. "Prenatal care in developing countries: the World Health Organization technical working group on antenatal care". Journal of the American Medical Women's Association, 50(5), 182-186.

Bhatia, M. R., and A. C. Gorter, 2007. "Improving access to reproductive and child health services in developing countries: are competitive voucher schemes an option?". Journal of International Development, 19(7), 975-981.

Celik, Y., and D. R. Hotchkiss, 2000. "The socio-economic determinants of maternal health care utilization in Turkey". Social Science \& Medicine, 50(12), 1797-1806.

Conway, K. S., and L. D. Kennedy, 2004. "Maternal depression and the production of infant health". Southern Economic Journal, 71(2), 260-286.

Corman, H., and M. Grossman, 1985. "Determinants of neonatal mortality rates in the US: a reduced form model". Journal of Health Economics, 4(3), 213-236.

Corman, H., T. J. Joyce, and M. Grossman, 1987. "Birth outcome production function in the United States". The Journal of Human Resources, 22(3), 339-360.

Currie, J., and E. Moretti, 2003. "Mother's education and the intergenerational transmission of human capital: evidence from college openings". The Quarterly Journal of Economics, 118(4), 1495-1532.

Gage, A. J., 2007. "Barriers to the utilization of maternal health care in rural Mali". Social Science \& Medicine, 65(8), 1666-1682.

Gage, A. J., and M. Guirlène Calixte, 2006. "Effects of the physical accessibility of maternal health services on their use in rural Haiti”. Population Studies, 60(3), 271-288.
Grossman, M., 1972. "On the concept of health capital and the demand for health". Journal of Political Economy, 80(2), 223-255.

Grossman, M., 1999. "The human capital model of the demand for health". NBER Working Paper 7078. Cambridge, MA: National Bureau of Economic Research.

Grossman, M., and T. J. Joyce, 1990. "Unobservables, pregnancy resolutions, and birth weight production functions in New York City". Journal of Political Economy, 98(5), 983-1007.

Guilkey, D. K., B. M. Popkin, J. S. Akin, and E. L. Wong, 1989. "Prenatal care and pregnancy outcome in Cebu, Philippines". Journal of Development Economics, 30(2), 241272.

Gwatkin, D. R., S. Rutstein, K. Johnson, E. Suliman, A. Wagstaff, and A. Amouzou, 2007. Socio-economic differences in health, nutrition, and population within developing countries: an overview. Washington, DC: The World Bank.

Habibov, N. N., 2011. "On the socio-economic determinants of antenatal care utilization in Azerbaijan: evidence and policy implications for reforms". Health Economics, Policy and Law, 6(2), 175-203.

Habibov, N. N., and L. Fan, 2011. "Does prenatal healthcare improve child birthweight outcomes in Azerbaijan? Results of the national demographic and health survey". Economics and Human Biology, 9(1), 5665.

Jewell, R. T., and P. Triunfo, 2006. "The impact of prenatal care on birthweight: the case of Uruguay". Health Economics, 15(11), 12451250.

Johar, M., 2009. "The impact of the Indonesian health card program: a matching estimator approach". Journal of Health Economics, 28(1), 35-53.

Joyce, T., 1994. "Self-selection, prenatal care, and birthweight among blacks, whites, and Hispanics in New York City". The Journal of Human Resources, 29(3), 762-794. 
Joyce, T., 1999. "Impact of augmented prenatal care on birth outcomes of Medicaid recipients in New York City". Journal of Health Economics, 18(1), 31-67.

Kaestner, R., 1999. "Health insurance, the quantity and quality of prenatal care, and infant health". Inquiry 36(2), 162-175.

Kaestner, R., T. Joyce, and H. Wehbeh, 1996. "The effect of maternal drug use on birth weight: measurement error in binary variables". Economic Inquiry, 34(4), 617-629.

Kotelchuck, M., 1994. "An evaluation of the Kessner adequacy of prenatal care index and a proposed adequacy of prenatal care utilization index". American Journal of Public Health, 84(9), 1414-1420.

Kyei, N. N. A., O. M. R. Campbell, and S. Gabrysch, 2012. "The Influence of distance and level of service provision on antenatal care use in rural Zambia". PLoS ONE, 7(10), 1-6.

Li, K., and D. J. Poirier, 2003b. "Relationship between maternal behavior during pregnancy, birth outcome, and early childhood development: an exploratory study". CESifo GmbH, CESifo Working Paper No. 1030. Munich. Retrieved September 25, 2013 from http://www.lib.uts.edu.au/sso/goto. php?url=http://search.ebscohost.com/login.a spx?direct=true $\& \mathrm{db}=\mathrm{ecn} \& \mathrm{AN}=0906370 \&$ si te=ehost-live

Lien, D. S., and W. N. Evans, 2005. "Estimating the impact of large cigarette tax hikes: the case of maternal smoking and infant birth weight". The Journal of Human Resources, 40(2), 373-392.

Liu, G. G., 1998. "Birth outcomes and the effectiveness of prenatal care". Health Services Research, 32(6), 805-823.

McNamee, P., L. Ternent, and J. Hussein, 2009. "Barriers in accessing maternal healthcare: evidence from low-and middle-income countries". Expert Review of Pharmacoeconomics \& Outcomes Research, 9(1), 4148.
Muchabaiwa, L., D. Mazambani, L. Chigusiwa, S. Bindu, and V. Mudavanhu, 2012. "Determinants of maternal healthcare utilization in Zimbabwe". International Journal of Economic Sciences and Applied Research, 5(2), 145-162.

Navaneetham, K., and A. Dharmalingam, 2002. "Utilization of maternal health care services in Southern India". Social Science \& Medicine, 55(10), 1849-1869.

Nguyen, H. T. H., L. Hatt, M. Islam, N. L. Sloan, J. Chowdhury, J.-O. Schmidt, and H. Wang, 2012. "Encouraging maternal health service utilization: an evaluation of the Bangladesh voucher program". Social Science \& Medicine, 74(7), 989-996.

Reichman, N. E., H. Corman, K. Noonan, and D. Dave, 2009. "Infant health production functions: what a difference the data make". Health Economics, 18(7), 761-782.

Reichman, N. E., and M. J. Florio, 1996. "The effects of enriched prenatal care services on Medicaid birth outcomes in New Jersey". Journal of Health Economics, 15(4), 455476.

Rosenzweig, M. R., and P. T. Schultz, 1982. "The behaviour of mothers as inputs to child health: the determinants of birth weight, gestation, and rate of fetal growth". In V. R. Fuchs (Ed.), Economic aspects of health (pp. 53-87). Chicago: University of Chicago Press.

Rosenzweig, M. R., and T. P. Schultz, 1983. "Estimating a household production function: heterogeneity, the demand for health inputs, and their effects on birth weight". Journal of Political Economy, 91(5), 723746.

Rous, J. J., R. T. Jewell, and R. W. Brown, 2004. "The effect of prenatal care on birthweight: a full-information maximum likelihood approach". Health Economics, 13(3), 251264.

Sepehri, A., S. Sarma, W. Simpson, and S. Moshiri, 2008. "How important are individual, household and commune characteris- 
tics in explaining utilization of maternal health services in Vietnam?". Social Science \& Medicine, 67(6), 1009-1017.

Steer, P. J., 2000. "Maternal hemoglobin concentration and birth weight". The American Journal of Clinical Nutrition, 71 (Supplemen), 1285S-1287S.

Warner, G., 2003. "The association between maternal depression and prenatal care adequacy". The Review of Black Political Economy, 30(3), 39-53.

Wooldridge, J. M., $4^{\text {th }}$ eds., 2009. Introductory econometrics: a modern approach. Mason, Ohio: South-Western Cengage Learning.

World Health Organization, 2005. The World Health report 2005: make every mother and child count. Geneva: World Health Organization. 